\title{
Antioxidant potantials of Helvella leucomelaena and Sarcosphaera coronaria
}

\begin{abstract}
The present study aimed to determine the total antioxidant status (TAS), total oxidant status (TOS) and oxidative stress index (OSI) of ethanol extracts of Helvella Leucomelaena (Pers.) Nannf and Sarcosphaera coronaria (Jacq.) J. Schröt. Mushrooms collected from Gaziantep province. TAS, TOS and OSI values were determined with Rel Assay Diagnostics kits. It was determined that the TAS values of H. leucomelaena and S. coronaria mushrooms were 2.367 and 1.066 , respectively, and the TOS values were 55.346 and 41.662 , respectively. OSI values were calculated as 2.338 and 3.909 for H. leucomelaena and S. coronaria mushrooms, respectively. As a result, it has been determined that fungi have high oxidant levels despite antioxidant potential
\end{abstract}

Keywords: helvella leucomelaena, sarcosphaera coronaria, antioxidant, oxidant, oxidative stress.

\author{
Volume 6 Issue I - 2018 \\ Mustafa Sevindik,' Hasan Akgul,' Ali İmran \\ Korkmaz,' İsmail Sen ${ }^{3}$ \\ 'Department of Biology,Akdeniz University, Turkey \\ ${ }^{2}$ Faculty of Science and Literature, Muğla Sıtkı Koçman \\ University, Turkey
}

Correspondence: Mustafa Sevindik, Department of Biology, Faculty of Science, Akdeniz University, Turkey, Tel 902423102348 , Fax 905327484228, Email sevindik27@gmail.com

Received: October 15, 2017| Published: February 0I, 2018

\section{Introduction}

Mushrooms have long been used for nutritional and medical purposes. ${ }^{1}$ They are rich in protein and amino acids, as well as their texture and flavour, low in calories and are considered a nutritious food. ${ }^{2}$ In addition to their nutritive properties, they are considered as a significant source of medicinal substances due to their important biologically active compound content. ${ }^{3,4}$ Because of the bioactive compounds they include, they play an important role in the prevention of diseases such as hypertension, hypercholesterolemia and cancer. ${ }^{5}$ Mushrooms were reported as therapeutic agents beneficial for the prevention or alleviation of bacterial, viral, fungal and parasitic infections. ${ }^{6,7}$

Uncontrolled production of free radicals in metabolism causes the onset of diseases such as cancer, rheumatoid arthritis, cirrhosis, atherosclerosis, cardiovascular diseases, neurological diseases, as well as processes such as aging. ${ }^{8-10}$ However, antioxidant supplements or foods that contain antioxidants could be used to reduce the oxidative damage in the human body. ${ }^{10}$ Mushrooms could also help reduce the negative effects of oxidative damage due to their antioxidant properties.

The present study aimed to determine the total antioxidant status (TAS), total oxidant status (TOS) and oxidative stress index (OSI) of ethanol extracts of Helvella Leucomelaena (Pers.) Nannf. (Figure 1) and Sarcosphaera coronaria (Jacq.) J. Schröt. (Figure 2) mushrooms collected from Gaziantep province. These species are cup shaped and grows similar habitats. Although, H. leucomelaena is edible species, $S$. coronaria is poisonous species. Especially, S. coronaria is a fatal species when consumed raw. So, we try to compare TAS, TOS and OSI level of these edible and poisonous species in the present study.

\section{Materials and methods}

Macrofungi specimens were collected from Dülükbaba Picnic Area-Pine Forest in Gaziantep province at 2016. In the field studies, morphological and ecological characters of the specimens were recorded and they photographed in the daylight conditions. After the field studies, the specimens were brought to laboratory with suitable conditions. The microscopic characters of the specimens such as spores shapes and sizes, ascus structures etc. were determined by mounting $3 \% \mathrm{KOH}$ by using light microscope. The specimens were identified morphologically by references of Dissing, ${ }^{11}$ Hansen and Knudsen ${ }^{12}$ and Breintenbach \& Kränzlin. ${ }^{13}$ The indentified specimens were deposited at the laboratory of Gaziantep University.

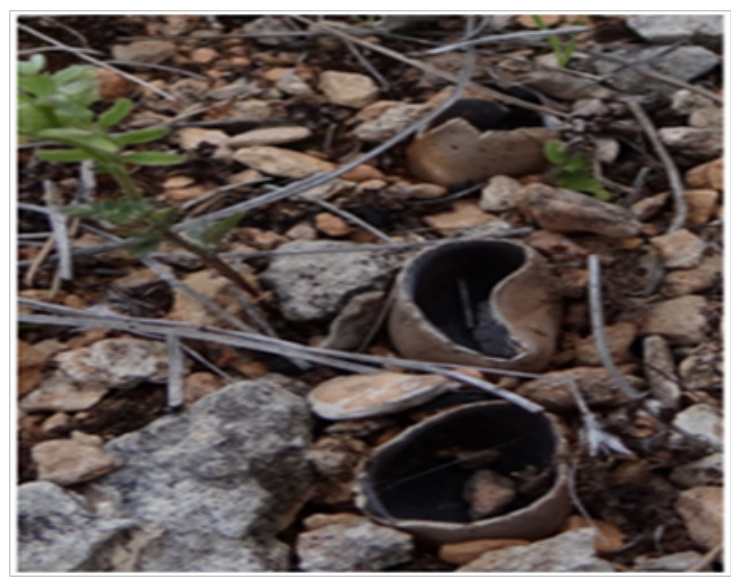

Figure I Helvella Leucomelaena.

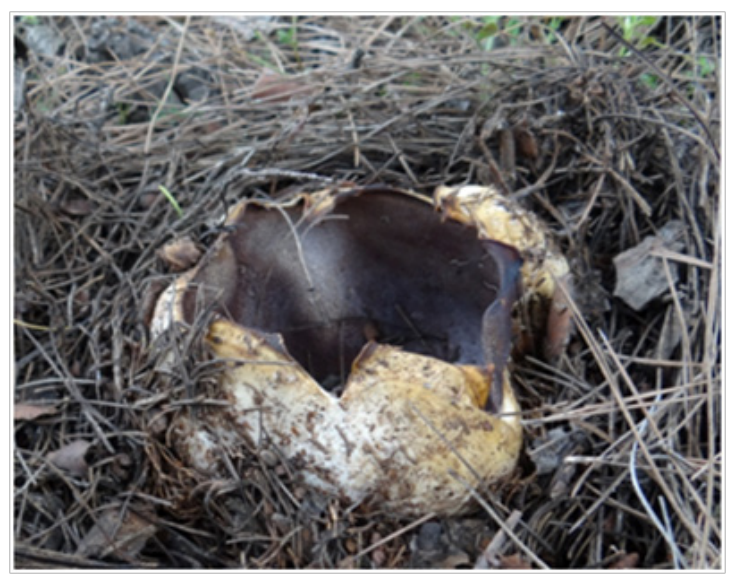

Figure 2 Sarcosphaera coronaria. 
Table I TAS, TOS and OSI values of fungal samples

\begin{tabular}{llll}
\hline Samples & TAS $(\mathbf{m m o l} / \mathbf{L})$ & TOS $(\mu \mathrm{mol} / \mathbf{L})$ & OSI $($ TOS/(TASx 10$))$ \\
\hline H. leucomelaena & 2.367 & 55.346 & 2.338 \\
S. coronaria & 1.066 & 41.672 & 3.909
\end{tabular}

Specimens collected from the field were dried in an incubator at $40^{\circ} \mathrm{C}$. After drying, a $30 \mathrm{gr}$ sample was weighed and pulverized with a mechanical grinder. It was then extracted with ethanol on a soxhlet apparatus at $50^{\circ} \mathrm{C}$ (BUCHI Extraction System Model B-811). Extracts that were concentrated under pressure with a rotary evaporator (BUCHI Rotavapor Model R-144) were stored at $+4^{\circ} \mathrm{C}$ until tested.

\section{Determination of the TAS,TOS and OSI values}

Rel Assay brand commercial kits (Rel Assay Kit Diagnostics, Turkey) were used to determine of mushroom ethanol extract TAS and TOS values. For the TAS value determination, Trolox was used as a calibrator and the values obtained were expressed asmmol Trolox equiv. /L. Hydrogen peroxide was used as the TOS calibrator and the values obtained were reported as $\mu \mathrm{mol} \mathrm{H}_{2} \mathrm{O}_{2}$ equiv/L. ${ }^{14,15}$ For the determination of OSI values, the units of TAS and TOS units were equalized and the proportion between the TOS and TAS values were calculated. Thus, mushroom oxidative stress indices were determined as percentages. ${ }^{15}$

\section{Result and discussion \\ TAS, TOS and OSI values}

Mushroom ethanol extract TAS ( $\mathrm{mmol} / \mathrm{L})$, TOS $(\mu \mathrm{mol} / \mathrm{L})$ and OSI values were determined in the study and the results are presented in Table 1.

Mushrooms contain several bioactive compounds. Due to the effects of these bioactive compounds, mushrooms are considered to be a good source of natural antioxidants. ${ }^{16}$ In the present study, antioxidant potential of both mushroom species were determined. Thus, both TAS and TOS values of H. leucomelaena were found to be higher than that of $S$. coronaria. The OSI values that demonstrate the rate at which the antioxidant compounds in the mushroom tolerate the oxidant compounds were 2.338 for H. leucomelaena and 3.909 for $S$. coronaria. TAS values were determined for various mushrooms as follows: Tricholoma terreum (Schaeff.) P. Kumm: 0.38, Coprinus micaceus (Bull.) Fr.: 0.46, Omphalotus olearius (DC.) Singer: 2.83, Pleurotus eryngii (DC.) Quél.: 1.93, Auricularia polytricha (Mont.) Sacc.: 0.93, Fomitopsis pinicola (Sw.) P. Karst: 1.57 and Geastrum pectinatum Pers.: $1.28 \mathrm{mmol} / \mathrm{L} .{ }^{17-22}$ TOS values were determined as 16.76 for $T$. terreum, 16.87 for C. micaceus, 2.03 for F. pinicola, 13.86 for $G$. pectinatum, and 8.26 for $O$. olearius. ${ }^{17-20}$ Compared to these studies, the TAS values of $H$. leucomelaena were higher than those of all the above mentioned mushrooms except $O$. olearius and the TAS value of $S$. coronaria was lower when compared to F. pinicola, G. pectinatum, P. eryngii and O. olearius. Also, It has been determined that the TOS values of the H. leucomelaena and $S$. coronaria mushroom are higher than the TOS values of the fungi in the literature. The high $H$. leucomelaena TAS value indicated that it had more antioxidant potential than the others. However, the high TOS value indicated that higher amounts of oxidative compounds were formed by environmental and metabolic factors in the mushroom. The oxidative stress index, which indicates the extent to which the oxidative factors associated with environmental and internal factors affect the antioxidant system, was found to be lower than the OSI value of $T$. terreum. The high $H$. leucomelaena TAS value indicated that this mushroom can be consumed as a good natural antioxidant source. However, considering the TOS and OSI values of this mushroom, it was suggested to consume the mushrooms collected from more suitable regions based on oxidative stress potential.

\section{Conclusion}

Analysis results demonstrated that both $H$. leucomelaena and $S$. coronaria mushrooms had antioxidant potential. However, the presence of high oxidant levels demonstrated the oxidative stress potential of the mushrooms. It was recommended to be careful in consumption of mushrooms collected from these regions in particular. TAS and TOS levels of edible species, H. leucomelaena is higher than the poisonous species. So, it can be said that this species can be consumed as natural antioxidant sources under the controlled conditions. But, this species is not preferred by local people of Turkey. Also, $S$. coronaria is known by local people and it consumed some villages of Turkey by cooking, although it is a poisonous species. In the further studies, the antioxidant levels of other species might be determined for using as natural antioxidant sources, and it needs to determined safely usage methods of poisonous species such $S$. coronaria, which has high antioxidant status.

\section{Acknowledgements}

None.

\section{Conflict of interest}

The author declares no conflict of interest.

\section{References}

1. Barros L, Ferreira MJ, Queiros B, et al. Total phenols, ascorbic acid, $\beta$ carotene and lycopene in Portuguese wild edible mushrooms and their antioxidant activities. Food chemistry. 2007;103(2):413-419.

2. Cheung LM, Cheung PC, Ooi VE. Antioxidant activity and total phenolics of edible mushroom extracts. Food chemistry. 2003;81(2):249-255.

3. Sevindik M. Mushrooms as Natural Antioxidant Agents. $J$ Tradit Med Clin Natur. 2017;7:e140.

4. Devi P, Rodrigues C, Naik CG, et al. Isolation and characterization of antibacterial compound from a mangrove-endophytic fungus, Penicillium chrysogenum MTCC 5108. Indian J Microbiol. 2012;52(4):617-623.

5. Muthu N, Shanmugasundaram K. Proximate and mineral compositions of edible mushroom Agrocybe aegerita. Journal of Pharmacognosy and Phytochemistry. 2016;5(1):116.

6. Murcia MA, Tome MM, Jimenez AM, et al. Antioxidant activity of edible fungi (truffles and mushrooms):losses during industrial processing. $J$ Food Prot. 2002;65(10):1614-1622.

7. Elmastas M, Isildak O, Turkekul I, et al. Determination of antioxidant activity and antioxidant compounds in wild edible mushrooms. Journal of Food Composition and Analysis. 2007;20(3):337-345.

8. Wong JY, Chye FY. Antioxidant properties of selected tropical wild edible mushrooms. Journal of Food Composition and Analysis. 2009;22(4):269-277. 
9. Palencia LAP. Chemical characterization, bioactive properties, and pigment stability of polyphenolics in açai (Euterpe Oleracea Mart.). USA: Texas A\&M University; 2009. 182 p.

10. Halliwell B, Gutterridge JM. Antioxidant activity of burdock its scavenging effect on free radical and active of $50 \%$ ethaolic red axtract. Journal of Food Science. 2003;68(1):21-25.

11. Dissing H. The genus Helvella in Europe with specieal emphasis on the species found in norden. Denmark: Dansk Botanisk Arkiv; 1966. 170 p.

12. Hansen L, Knudsen H. Nordic macromycetes (Ascomycetes). Denmark: Nordsvamp; 2000.

13. Breitenbach J, Kränzlin F. Fungi of Switzerland. Switzerland: Verlag Mykologia; 1984.

14. Erel O. A novel automated direct measurement method for total antioxidant capacity using a new generation, more stable ABTS radical cation. Clin Biochem. 2004;37(4):277-285.

15. Erel O. A new automated colorimetric method for measuring total oxidant status. Clin Biochem. 2005;38(12):1103-1111.

16. Boonsong S, Klaypradit W, Wilaipun P. Antioxidant activities of extracts from five edible mushrooms using different extractants. Agriculture and Natural Resources. 2016;50(2):89-97.
17. Akgül H, Sevindik M, Akata I, et al. Macrolepiota procera (Scop.) Singer Mantarının Ağır Metal İçeriklerinin ve Oksidatif Stres Durumunun Belirlenmesi. Süleyman Demirel Üniversitesi Fen Bilimleri Enstitüsü Dergisi. 2016;20(3):504-508.

18. Sevindik M, Akgul H, Bal C. Determination of Oxidative Stress Status of Ompholatus olearius Gathered from Adana and Antalya Provinces in Turkey. Sakarya Üniversitesi Fen Bilimleri Enstitüsü Dergisi; 2017. 21(3):324-327.

19. Sevindik M, Akgul H, Akata I, et al. Fomitopsis pinicola in healthful dietary approach and their therapeutic potentials. Acta Alimentaria. 2017;46(4):464-469.

20. Sevindik M, Akgul H, Bal C. Geastrum pectinatum as an Alternative Antioxidant Source with some Biochemical Analysis. Medical Mycology: Open Access. 2017;3(2):25.

21. Yildirim NC, Turkoglu S, Yildirim N, et al. Antioxidant properties of wild edible mushroom Pleurotus eryngii collected from Tunceli province of Turkey. DJNB. 2012;7(4):1647-1654.

22. Avci E, Cagatay G, Avci GA, et al. An Edible Mushroom with Medicinal Significance; Auricularia polytricha. Hittite Journal of Science \& Engineering. 2016;3(2):111-116. 